\title{
A GESTÃo de PROJETOS COMO APOIO AO PROCESSO DE PRODUÇÃO DE UM PERIÓDICO CIENTÍFICO
}

\author{
THE PROJECT MANAGEMENT TO SUPPORT PRODUCTION \\ PROCESS OF A SCIENTIFIC JOURNAL
}

Fabrício Martins Lacerda $^{1}$
Cristina Dai Prá Martens $^{2}$
Emerson Antonio Maccari $^{3}$

RESUMO

A evolução do conceito de projetos e o desenvolvimento e aceitação das metodologias e abordagens para seu planejamento e gerenciamento tem permitido sua aplicabilidade a diferentes áreas, realidades e culturas organizacionais. A busca por métodos e ferramentas capazes de conduzir seus projetos a um final bem-sucedido, a exemplo de um periódico científico, tem motivado muitas organizações a buscar, nas boas práticas de gestão de projetos, um melhor planejamento e gerenciamento. Nesse contexto, o objetivo deste trabalho é analisar o processo de produção de um periódico científico sob a ótica da gestão de projetos. Foi desenvolvido um estudo de caso único que verificou a aplicação dos processos de gestão de escopo, prazo e custo do projeto de produção de uma revista científica de especialidade médica. Como resultados, destaca-se que, mesmo não tendo conhecimento das boas práticas de gestão de projetos, a organização aplica algumas de suas ferramentas de maneira informal e embrionária. Foram identificados pontos que merecem atenção, pois impactam no atraso da veiculação da Revista. Proposições de melhorias foram apresentadas por meio da aplicação da metodologia da gestão de projetos, o que poderá contribuir para um melhor planejamento e gerenciamento do projeto.

PALAVRAS-CHAVE: Periódico científico. Editoração. Gestão de projetos.

\begin{abstract}
The advancement of the concept of projects and the development and acceptation of methodologies and approaches for its planning and management, has permitted its applicability in different areas, realities and organizational cultures. The search for methods and instruments capable of conducting your project to a successful accomplishment, e.g. a scientific journal, has motivated many organizations to enhance planning and management by resorting to good project management practices. In this context, the objective of this paper is to analyze the process of making a scientific journal within a perspective of project management. A case study was developed that verified the application of management processes of scope, deadline and costs of the project of producing a specialized medical scientific journal. Within the results, emphasis goes to the fact that despite not having information about good project management practices, the organization applies some of its tools informally and embryonically. Some elements that impact on the delay of the magazines diffusion were identified as in need of enhancement. Improvement proposals were presented by applying project management methodologies that can contribute with enriched planning and project management.
\end{abstract}

KEYWORDS: Scientific Journal. Editing. Project Management.

\footnotetext{
1 Doutorando em Administração pela Universidade Nove de Julho (PPGA/UNINOVE). E-mail: fabriciomlacerda@gmail.com

${ }^{2}$ Professora do Programa de Pós-Graduação em Administração da Universidade Nove de Julho. E-mail: cristinadm@uninove.br

${ }^{3}$ Professor do Mestrado Profissional em Administração - Gestão de Projetos - da Universidade Nove de Julho. E-mail: maccari@uninove.br
}

Enviado em: 31/07/2015 - Aceito em: 14/09/2015 


\section{INTRODUÇÃO}

O reconhecimento que a gestão de projetos é uma ferramenta eficiente para lidar com novas ou complexas atividades tem ocorrido nos últimos 30 anos (MUNNS; BJEIRMI, 1996). Contudo, nos últimos dez anos, tem sucedido um rápido crescimento e aceitação da gestão de projetos (IKA, 2009; KERZNER, 2011), de suas ferramentas, metodologias e abordagens de gestão que compõem a disciplina, sendo aplicadas a diferentes áreas, com finalidades diversas, e em distintas culturas (CRAWFORD; POLLACK; ENGLAND, 2006). Portanto, não é de se surpreender que mais organizações estejam aceitando a gestão de projetos como caminho para um melhor planejamento (KERZNER, 2011).

Muitas organizações estão adaptando suas operações e processos como projetos, buscando planejar, gerenciar e concluir seus produtos e serviços com mais sucesso. Por isso, é crescente a pressão sobre os gestores por um planejamento, integração e controle do cronograma na busca de um melhor desempenho da organização (IBBS; KWAK, 1997).

A aplicação do conhecimento produzido na área de gestão de projetos na indústria, comércio e serviços às ações das organizações sem fins lucrativos é uma iniciativa natural. Contudo, o conhecimento da metodologia, mesmo já sendo demandada por essas organizações, tem encontrado dificuldade de profissionalização, impedido um desenvolvimento mais acelerado (RUGGERI, 2011). Para o autor, há necessidade de produção de trabalhos que reforcem a relação entre a gestão oriunda do contexto não lucrativo com as boas práticas de gestão de projetos.

Nos últimos anos, o conceito de projetos tem sido discutido e evoluído (RABECHINI, CARVALHO; LAURINDO, 2002). Projeto é definido como sendo uma organização temporária e processo estabelecido para alcançar uma meta específica sob as restrições de tempo, orçamento e outros recursos (SHENHAR; DVIR, 2010). Por outro lado, o enfoque da gestão de projetos é relativamente novo, sendo aplicável para qualquer iniciativa pontual (única) relacionada a um objetivo final específico (KERZNER, 2011). A função da gestão de projetos, segundo Munns e Bjeirmi (1996), inclui definir a exigência de trabalho, buscando estabelecer sua extensão, o planejamento da execução, o monitoramento do progresso, ajustando os desvios do plano e alocando os recursos necessários. Na definição de Shenhar e Dvir (2010), a gestão de projetos é o conjunto de atividades administrativas necessárias para levar um projeto a um final bem-sucedido.

Neste contexto, o conceito da gestão de projetos pode ser aplicado a diferentes realidades, a exemplo do projeto de elaboração de um periódico científico. Um periódico científico, para que possa ser considerado de boa qualidade, precisa publicar bons artigos, manter sua periodicidade e ser facilmente encontrado, entre outros indicadores (FERREIRA; NASCIMENTO, 2002; JOB; GOELLNER, 2015). Todavia, essas características são dependentes umas das outras, compondo um fluxo contínuo que deve ser mantido Com foco na regularidade, Ferreira e Krzyzanowski (2003) descrevem que este é um dos critérios obrigatórios no processo de avaliação dos periódicos, devendo ser disponibilizados, pontualmente, de acordo com a periodicidade estabelecida. A periodicidade faz parte dos 
procedimentos específicos na avaliação de desempenho (forma), recebendo um ponto a menos pelo atraso da Revista, ou, por apresentar, com frequência, acúmulo de edições (KRZYZANOWSKI; FERREIRA, 1998). Para Job e Goellner (2015) deve-se conceder um ponto se a publicação cumprir com a periodicidade estabelecida.

Tendo em vista essa realidade, o principal objetivo deste estudo é analisar o processo de produção de um periódico científico sob a ótica da gestão de projetos. O projeto trata-se da Revista Especializada, nome fictício utilizado com o intuito de preservar a imagem da organização - uma Associação sem fins lucrativos - e da própria Revista, que tem como missão registrar a produção científica no âmbito da medicina, para promover o estudo, aprimoramento e atualização dos profissionais de uma especialidade médica. Para tanto, pretende-se responder à seguinte questão de pesquisa: como a aplicação da metodologia da gestão de projetos pode contribuir para um melhor planejamento e gerenciamento do processo de produção de um periódico científico? Deste modo, por meio de sua abordagem empírica, com a aplicação da metodologia da gestão de projetos à produção de um periódico científico, o estudo visa contribuir para o aprimoramento dessa atividade fazendo uso de conceitos e práticas sobre gerenciamento de escopo, custo e tempo.

Este estudo é apresentado em cinco seções, incluindo esta introdução. A segunda seção apresenta os aspectos teóricos sobre o tema. Em seguida, o método de pesquisa é descrito, e na quarta seção a análise dos resultados é apresentada. Por fim, são feitas as considerações finais do estudo.

\section{REFERENCIAL TEÓRICO}

Nesta seção é feita uma abordagem dos aspectos conceituais pertinentes à gestão de projetos que, segundo Kerzner (2011), é caracterizada por métodos de reestruturação da administração e adaptação de técnicas especiais de gestão. Para o autor, a finalidade de se adotar a gestão de projetos é a busca por melhor controle e utilização dos recursos existentes.

\section{Aspectos Conceituais da Gestão de Projetos}

A denominação da tríplice restrição, triângulo de ferro, e também denominada de objetivos primários de projetos, baseia-se no escopo (ou desempenho técnico), prazo e custo (JHA; IYER, 2007; IKA, 2009; CARVALHO; RABECHINI, 2011). Segundo Shenhar e Dvir (2010) a maioria dos projetos ainda fracassa por não atingirem seus objetivos primários de escopo, prazo e custo. Os resultados de pesquisas realizadas por eles em mais de 600 projetos nos setores comerciais, governamentais e sem fins lucrativos em vários países, diagnosticaram que $85 \%$ dos projetos não cumpriram com as metas de tempo e orçamento iniciais, com uma média de excesso de atrasos de $70 \%$ e aumento médio de $60 \%$ no orçamento. Para os mesmos autores, o fracasso de muitos projetos está condicionado aos erros gerenciais, à falta da avaliação crítica das incertezas e complexidades, ao não cumprimento das metas de tempo, orçamento e dos objetivos propostos. 
Por outro lado, considerando as mudanças nas filosofias das teorias das organizações, influenciadas pela gestão de projetos na administração, Kerzner (2011) aborda que o apoio à gestão de projetos e a demonstração de confiança na metodologia fazendo parte da cultura organizacional, poderá levar a empresa a alcançar a excelência em gestão de projetos. Segundo Kerzner (2011), dificilmente, duas empresas irão gerenciar projetos da mesma forma, por isso, a implantação da gestão de projetos deve ter por base a cultura organizacional. A cultura organizacional divide o projeto em fases do ciclo vida com a finalidade de fornecer uma metodologia para a uniformidade no planejamento do projeto, quando, empresas privadas e até mesmo públicas, preparam listas de verificação das atividades que devem ser consideradas em cada fase (KERZNER, 2011).

Os projetos variam de tamanho e complexidade, mas todos os projetos podem ser mapeados para a estrutura de ciclo de vida dividido em: início do projeto; organização e preparação; execução do trabalho do projeto; e encerramento do projeto (PMI, 2013). Neste sentido, empresas vêm desenvolvendo manuais de procedimentos com foco na gestão de projetos e na melhor estrutura de trabalho com base nas fases do ciclo de vida. Esses manuais vão ao encontro das metodologias da gestão de projetos, que são os processos repetitivos utilizados em cada um dos projetos (KERZNER, 2011).

\section{Metodologia da Gestão de Projeto}

A metodologia da gestão de projetos da organização pode melhorar o processo de planejamento do projeto, bem como fornecer algum grau de padronização e consistência (KERZNER, 2011). Essa metodologia está estruturada no Project Management Body of Knowledge $\left(\mathrm{PMBoK}^{\circledR}\right)$, no qual são organizadas as áreas de conhecimento de integração, escopo, tempo, custo, risco, comunicação, qualidade, aquisição e recursos humanos (CARVALHO; RABECHINI, 2011), e stakeholders recentemente agregada (PMI, 2013).

No conjunto, as dez áreas de conhecimento interagem com os grupos dos seguintes processos: iniciação, planejamento, execução, monitoramento e controle, e encerramento, o que é sugerido pelo PMBoK® (PMI, 2013). Em cada área de conhecimento são apresentados processos específicos e separados conforme o grupo de processos, com a finalidade de nortear a aplicação dos conhecimentos e habilidades da gestão do projeto durante a execução do projeto (ALMEIDA; MIGUEL; CARVALHO, 2008).

A Figura 1 mostra a relação entre os cinco grupos de processos da gestão de projetos e as dez áreas de conhecimento, definidos pelo PMBoK® (PMI, 2013). 


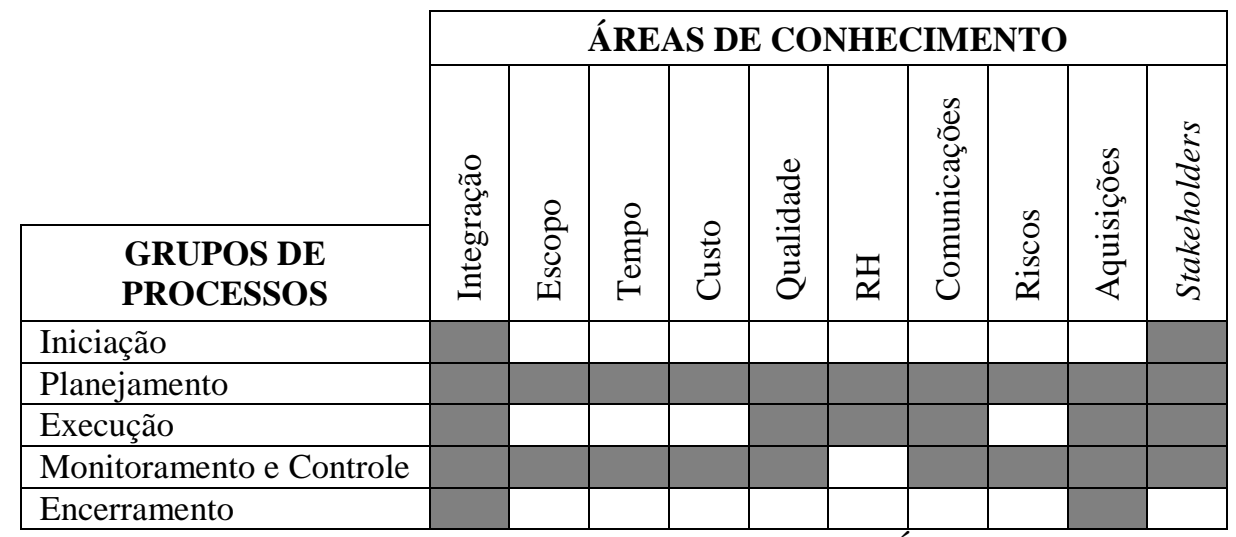

FIGURA 1 - Grupo de Processos da Gestão de Projetos e Âreas de Conhecimento

Legenda: célula cinza identifica processos relacionados

Fonte: Elaborada pelos autores com base no $\mathrm{PMBoK}^{\circledR}$ (PMI, 2013).

Os processos do grupo de iniciação definem e autorizam um novo projeto ou uma nova fase de um projeto existente, definindo, também, o escopo e os recursos financeiros iniciais. Nos processos de iniciação são apresentados os objetivos do projeto, uma declaração inicial do escopo, das entregas, da duração, bem como uma previsão dos recursos para a análise do investimento da organização (PMI, 2013).

No grupo dos processos de planejamento o escopo total é estabelecido, os objetivos são definidos e refinados de modo a desenvolver o caminho de ação indispensável para atingir esses objetivos. O plano de gerenciamento do projeto, principal fonte de informação de planejamento, execução, monitoramento, controle e encerramento do projeto, e a documentação do projeto, são desenvolvidos como saídas deste grupo, nos quais são explorados os aspectos gerais de escopo, tempo, custos, qualidade, comunicação, riscos e aquisições. Manter atualizado esses documentos contribui para uma melhor precisão na elaboração do cronograma, dos custos e requisitos de recursos para cumprir o escopo definitivo para o projeto (PMI, 2013).

Segundo o PMI (2013), o grupo de processos de execução visa concluir o trabalho definido no plano de gerenciamento do projeto, coordenando pessoas e recursos, além de integrar e realizar as atividades do planejamento do projeto. O grupo de processos de monitoramento e controle tem como objetivo acompanhar, revisar e regular o progresso e o desempenho do projeto, de modo a identificar as áreas nas quais serão necessárias alterações no plano de gerenciamento do projeto, além de iniciá-las (PMI, 2013). Almeida, Miguel e Carvalho (2008), descrevem que este grupo fornece feedback para as atualizações do plano de gerenciamento do projeto no início de cada fase.

No grupo de processos de encerramento são executados os processos que formalizam todo o encerramento das atividades de todos os grupos de processos, ou seja, o projeto, a fase ou quaisquer obrigações contratuais são finalizados (PMI, 2013).

O Quadro 1 apresenta os processos de gestão relacionados aos objetivos primários da gestão de projetos, foco do objeto deste estudo. 
QUADRO 1 - Processos de gestão dos objetivos primários da gestão de projetos

\begin{tabular}{|l|l|l|}
\hline \multicolumn{2}{|c|}{ Gestão do Escopo } & \multicolumn{2}{c|}{ Gestão do Tempo } & \multicolumn{1}{c|}{ Gestão dos Custos } \\
\hline Coletar os requisitos & Definir as atividades & \multirow{2}{*}{ Estimar os custos } \\
\hline Definir o escopo & Sequenciar as atividades & \\
\hline Criar a EAP & Estimar os recursos das atividades & \multirow{2}{*}{ Determinar o orçamento } \\
\hline Verificar o escopo & Estimar as durações das atividades & \\
\hline \multirow{2}{*}{ Controlar o escopo } & Desenvolver o cronograma & \multirow{2}{*}{ Controlar os custos } \\
\cline { 2 - 2 } & Controlar o cronograma & \\
\hline
\end{tabular}

Fonte: Elaborado pelos autores com base no PMBoK $^{(8)}$ (PMI, 2013).

A seguir, é realizada uma breve abordagem das áreas de escopo, tempo e custo, bem como dos seus respectivos processos de gestão.

\section{Gestão do Escopo}

Escopo do projeto é considerado todo trabalho que deverá ser desenvolvido na área do projeto, podendo estar ligado ao produto ou serviço (CARVALHO; RABECHINI, 2011). O escopo refere-se à definição dos limites entre determinadas tarefas, atividades, contratos, atribuições, responsabilidades e missões, ou seja, é através dele que é definido onde termina um trabalho e começa outro (DINSMORE, 1992).

Os processos de gestão do escopo do projeto considerados pelo PMBoK® (PMI, 2013) são: a) Coletar os requisitos: o processo de definição e documentação das necessidades das partes interessadas de modo que os objetivos sejam alcançados; b) Definir o escopo: o processo de desenvolvimento de uma descrição detalhada do projeto e do produto; c) Criar a Estrutura Analítica do Projeto - EAP: consiste no processo de subdivisão do trabalho e das entregas maiores do projeto em componentes menores, e mais facilmente gerenciáveis; d) Verificar o escopo: processo de formalização e busca pela aceitação das entregas terminadas do projeto; e) Controlar o escopo: é o processo de monitoramento do progresso do escopo do projeto e também do produto, e também da gestão das alterações realizadas na linha de base do escopo.

A Estrutura Analítica do Projeto - EAP é uma ferramenta utilizada no processo de decomposição e detalhamento do escopo. É por meio da EAP que os trabalhos são hierarquizados e decompostos (para baixo) e integrados (para cima), com a finalidade de auxiliar um melhor gerenciamento na execução do projeto. Para cada parte do trabalho decomposto é preciso levar em consideração: objetivo, entregas, programação, orçamento e responsabilidades (CARVALHO; RABECHINI, 2011). Essas atividades proporcionam uma base para a estimativa, desenvolvimento do cronograma, execução e monitoramento, e controle das atividades do projeto (PMI, 2013).

Os processos usados para gerenciar o escopo, assim como as ferramentas e técnicas de suporte, podem variar de acordo com área de aplicação e, normalmente, são definidos como parte do ciclo de vida do projeto (PMI, 2013). Para Dinsmore (1992), o responsável pela 
gestão do escopo do projeto auxilia na definição exata do que precisa ser feito por parte de cada indivíduo que atua no projeto, tornando mais fácil atingir os objetivos propostos. Kerzner (2011), ao descrever que a maioria dos projetos não mantém o mesmo plano do início ao término, sugere que seja realizada análise de compensações, que são sempre baseadas nas restrições do projeto, pois as mesmas terão impacto e poderão sacrificar tempo, custos ou desempenho, quando, geralmente, o sacrifício de um item causa reflexo em outros.

\section{Gestão do Tempo}

"A administração disciplinada do tempo é uma das chaves para o gerenciamento de projetos eficaz" (KERZNER, 2011, p. 177). Contudo, para uma adequada gestão de tempo, é necessário que a gestão de escopo tenha sido bem conduzida, visto que, toda a gestão dos prazos é delimitado pelas decisões de escopo tomadas (CARVALHO; RABECHINI, 2011).

Os processos de gestão do tempo do projeto considerados pelo PMBoK® (PMI, 2013) são: a) Definir as atividades: é o processo de identificação das ações específicas a serem realizadas para produzir as entregas do projeto; b) Sequenciar as atividades: consiste no processo de identificação e documentação dos relacionamentos entre as atividades do projeto; c) Estimar os recursos das atividades: é o processo de estimativa dos tipos e quantidades de material, pessoas, equipamentos ou suprimentos que serão necessários para realizar cada atividade; d) Estimar as durações das atividades: estimativa mais próxima possível do número de períodos de trabalho que serão necessários para finalizar atividades específicas com os recursos previstos; e) Desenvolver o cronograma: é o processo de análise das sequências das atividades, suas respectivas durações, recursos necessários e restrições do cronograma para montar o cronograma do projeto; f) Controlar o cronograma: processo que visa o monitoramento do desenvolvimento do projeto para atualização do seu progresso e gerenciamento das mudanças no cronograma. "É sempre bom lembrar que esses processos interagem entre si e com as demais áreas de gerenciamento de projetos, em especial escopo e custo" (CARVALHO; RABECHINI, 2011, p. 106).

O cronograma é o documento que representa o planejamento do tempo em um projeto, apresentando a data planejada para início e término de cada atividade. Após aprovação do cronograma, o mesmo se torna um dos componentes do planejamento do projeto, sendo usado para avaliar e acompanhar o seu desempenho (XAVIER; CHUERI, 2008), e garantir que o projeto seja finalizado de acordo com o prazo previsto (DINSMORE; CAVALIERI, 2008). Khang e Myint, (1999) enfatizam que, associado ao tempo normal, estão custos normais e qualidade de desempenho normal e, com o tempo crítico, estão associados custos e qualidade fora de controle.

\section{Gestão dos Custos}

Para Kerzner (2011) o controle dos custos é igualmente importante tanto para as pequenas quanto para as grandes empresas. Na elaboração de um projeto, é preciso saber quanto ele custará (XAVIER; CHUERI, 2008), e para uma apropriada gestão de custos, é 
necessária uma adequada integração com as demais áreas de gestão do projeto, principalmente, com aquelas que compõem o triângulo dos objetivos primários de escopo, prazo e custo (CARVALHO; RABECHINI, 2011).

Os processos que compõem a gestão dos custos do projeto considerados pelo PMBoK® (PMI, 2102) são: a) Estimar os custos: é o processo de desenvolvimento de uma estimativa de custos dos recursos financeiros necessários para finalizar todas as atividades do projeto; b) Determinar o orçamento: processo de agregar todos os custos estimados de atividades individuais ou pacotes de trabalho, para estabelecer uma linha de base autorizada dos custos; c) Controlar os custos: consiste no processo de monitoramento do andamento do projeto para atualização do seu orçamento e gestão das alterações realizadas na linha de base dos custos. A gestão dos custos do projeto, com esses processos envolvidos, contribui para que o projeto seja terminado nos limites do orçamento aprovado (PMI, 2013), contudo, o desempenho dos custos do projeto deve ser monitorado e medido, regularmente, para identificar as alterações do planejamento (DINSMORE; CAVALIERI, 2008).

Carvalho e Rabechini (2011) descrevem que a orçamentação do projeto pode ser iniciada após concluir o processo de estimativas de custo, uma vez que seu objetivo é gerar a linha base de custo do projeto. Essa linha de base inclui todos os orçamentos autorizados, excluindo as reservas de gerenciamento (PMI, 2013). Portanto, a linha de base torna-se fundamental para a gestão dos custos, pois é através dela que o desempenho do projeto é medido, permitindo, ainda, estabelecer eventuais ações contingenciais se o realizado estiver se desviando do planejado (CARVALHO; RABECHINI, 2011).

\section{METODOLOGIA}

Este estudo foi desenvolvido com a finalidade de analisar o processo de produção de um periódico científico, sob a ótica da gestão de projetos. As estratégias de pesquisa adotadas basearam-se em uma pesquisa bibliográfica e um estudo de caso único, por se tratar de uma investigação empírica na qual um fenômeno contemporâneo é investigado (YIN, 2010). Deste modo, o projeto escolhido como objeto deste estudo é a Revista Especializada, uma publicação científica desenvolvida por uma Associação de Especialidade Médica.

São apresentadas por Yin (2010) seis fontes de evidência usadas mais comumente na realização dos estudos de caso: documentação, registros em arquivos, entrevistas, observação direta, observação participante e artefatos físicos. Essas fontes são altamente complementares e, na busca por um bom estudo de caso, deve-se usar tantas fontes quanto possível. Este estudo utilizou como fonte secundária a coleta de evidências por meio de documentos administrativos da organização, do Sistema de Gestão da Qualidade - SGQ (ISO 9001:2008), e do projeto.

Como fonte primária foram realizadas entrevistas semiestruturadas, guiadas por questões abertas, junto a duas profissionais envolvidas na atividade: a gestora responsável pelas atividades de planejamento, desenvolvimento e controle do processo de produção da 
Revista há 12 anos; a técnica responsável pela editoração, diagramação e fechamento da edição, que atua nessa atividade há cerca de 25 anos. A entrevista semi-estruturada é conduzida através de um roteiro, porém, permite ao entrevistador acrescentar novas questões (YIN, 2010). O roteiro de entrevista semi-estruturada utilizado para o levantamento de dados foi composto por 14 questões abertas e divididas em três focos principais, conforme resumido no Quadro 2.

QUADRO 2 - Roteiro de entrevista

\begin{tabular}{|l|c|l|}
\hline \multicolumn{1}{|c|}{ Foco Principal } & Questões & \multicolumn{1}{c|}{ Exemplo de Questões } \\
\hline $\begin{array}{l}\text { 1. Características gerais do } \\
\text { projeto. }\end{array}$ & 5 & $\begin{array}{l}\text { 1. Quais objetivos a empresa deseja atingir com o projeto? } \\
\text { 2. Como são realizadas as gestões de escopo, prazo e custo do } \\
\text { projeto? }\end{array}$ \\
\hline $\begin{array}{l}\text { 2. Informações dos processos } \\
\text { de produção do projeto. }\end{array}$ & 6 & $\begin{array}{l}\text { 6. Quem são os envolvidos no processo de produção do projeto? } \\
\text { 11. Quais fatores poderão impactar no cumprimento das fases e } \\
\text { na entrega final do projeto? }\end{array}$ \\
\hline $\begin{array}{l}\text { 3. Informações sobre os } \\
\text { processos de planejamento e } \\
\text { gerenciamento no decorrer } \\
\text { do ciclo de vida do projeto. }\end{array}$ & 3 & $\begin{array}{l}\text { 12. É utilizada alguma ferramenta para o planejamento do ciclo } \\
\text { de vida do projeto? Se sim, quais e como são utilizadas. } \\
\text { 13. Em sua opinião, quais os principais fatores que impactam } \\
\text { no atraso da revista? }\end{array}$ \\
\hline
\end{tabular}

Fonte: Elaborado pelos autores.

A coleta de dados também envolveu observação participante realizada por um dos autores deste estudo, que integra o quadro funcional da organização, sendo o responsável pela parte comercial do projeto. Deste modo, contando com múltiplas fontes de evidências, os dados convergem de maneira triangular, o que representa uma estratégia de análise de dados (YIN, 2010).

Para a realização da análise dos dados, foi dada preferência para a contextualização da situação-problema, priorizando a apresentação de resultados práticos (BIANCOLINO et al., 2012). Inicialmente, adotou-se a estratégia geral de descrição do caso (YIN, 2010), que auxilia no desenvolvimento de uma estrutura analítica descritiva para organizar o estudo de caso. Na sequência, foi adotada a técnica analítica de adequação ao padrão, proposta pelo mesmo autor, fazendo a comparação dos procedimentos adotados no caso estudado com os processos propostos pelo PMI (2013) para escopo, tempo e custo. Com base nisso, foi possível identificar os pontos que carecem de melhorias, que impactam de forma negativa no desenvolvimento do projeto, bem como apresentar proposições de melhorias.

\section{ANÁLISE DOS RESULTADOS}

Nos últimos anos, a Revista Especializada tem passado por expressiva reformulação interna com o objetivo de aprimorar o processo de seleção e edição dos artigos publicados. Vem consolidando sua posição de destaque no cenário científico da especialidade em âmbito mundial, sendo indexada nas principais bases de dados: National Library of Medicine (Medline), Embase, ISI Web of Knowledge, Scientific Eletronic Library Online (SciELO). Para Mueller (1999), a qualidade dos artigos, a regularidade na publicação e a facilidade de acesso, permitem ao periódico ser incluído em base de dados internacionais, possibilitando, ainda, aumento da sua visibilidade. O periódico é publicado bimestralmente, e os recursos 
financeiros utilizados para o desenvolvimento do projeto, advêm da veiculação de anúncios comerciais formalizados através de contratos anuais ou veiculações esporádicas por edição.

A Revista Especializada é editada por uma Associação científica e cultural de médicos especialistas. A organização possui natureza privada sem finalidade lucrativa, de capital nacional e, desenvolvendo suas atividades no setor de serviços, é a principal entidade representativa da especialidade no Brasil. Apesar de ter implantado o Sistema de Gestão da Qualidade - ISO 9001:2008, buscando a melhoria contínua da qualidade dos processos administrativos, visando maximizar a satisfação dos stakeholders, a associação tem enfrentado problemas na gestão dos projetos, principalmente, devido à falta de: planejamento, comprometimento dos colaboradores, apoio da alta direção, conhecimento de metodologias de gestão administrativa e, sobretudo, da gestão de projetos. Este contexto tem comprometido o desempenho e continuidade de alguns projetos, a exemplo da Revista Especializada, principalmente devido aos atrasos significativos que têm ocorrido no lançamento de suas edições, além de acarretar redução das fontes de receitas.

A seguir são apresentados os resultados das análises do processo de produção da Revista Especializada, sob a ótica da gestão de projetos, com base nos objetivos primários da gestão de projetos, nas edições dos últimos cinco anos (2010 a 2014).

\section{Gestão do Escopo do Projeto}

Para abordar a gestão do escopo do projeto de produção da Revista Especializada, foram utilizados os processos para coleta dos requisitos, a definição do escopo, a criação da EAP, a verificação do escopo e o seu controle, conforme proposto pelo PMI (2012). A coleta dos requisitos para definir e documentar as necessidades dos interessados é realizado de maneira informal e não abrange a todos os stakeholders. Deste modo, o primeiro processo para elaboração do escopo do projeto não é definido integralmente, podendo comprometer o alcance do objetivo proposto (PMI, 2013).

No processo de definição do escopo é necessário descrever, detalhadamente, o projeto e o produto. O projeto em análise tem seu escopo definido no documento do Sistema de Gestão da Qualidade (SGQ), que tem a finalidade de estabelecer a sistemática que busca padronizar o "processo de produção" da Revista, conforme Figura 2.

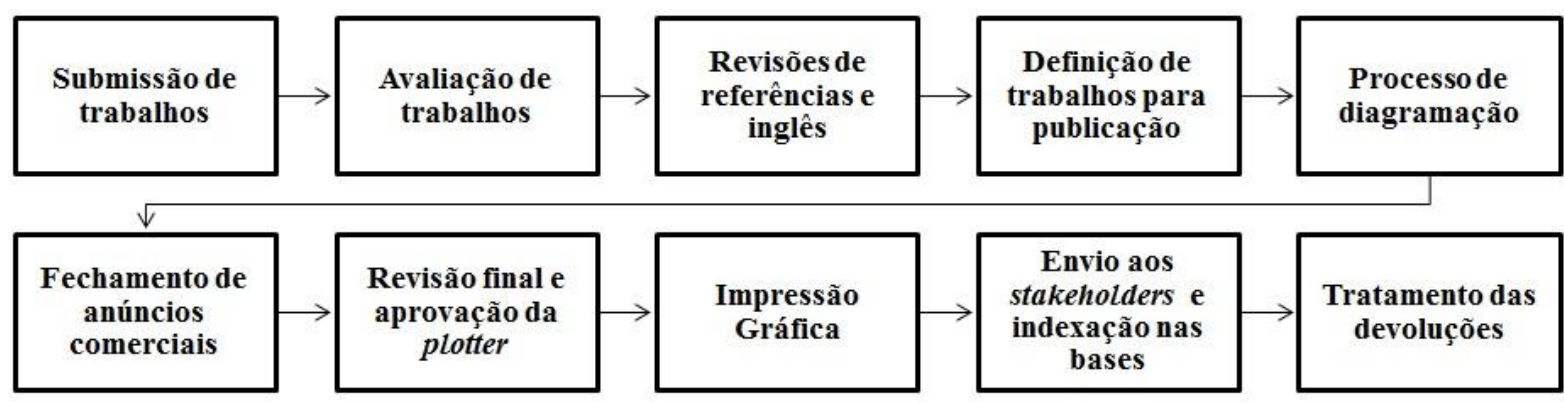

FIGURA 2 - Fluxo do processo de produção do projeto Fonte: os autores, pesquisa de campo. 
O escopo é definido da seguinte forma: a) É de responsabilidade do editor chefe acompanhar e monitorar as atividades previstas e descritas no documento; b) Todo trabalho deve ser submetido por meio do programa online, sendo os autores os responsáveis por todas as informações postadas e pela documentação exigida pelas normas aos autores; c) $\mathrm{Na}$ avaliação dos trabalhos, após a submissão dos artigos científicos, a gestora inicialmente verifica se o mesmo está adequado ao formato exigido pelas normas da Revista. Sendo necessário complementar as informações ou adequar o artigo, os autores são contatados por correio eletrônico para que façam os ajustes o mais breve possível. Estando adequado, o trabalho é encaminhado pela gestora ao editor chefe para que seja distribuído aos editores de seção, que então enviam aos revisores para análise. Assim que o trabalho é aceito, estará disponível para publicação; d) Os trabalhos aprovados para publicação são enviados pela gestora para as revisoras bibliográficas, serviço terceirizado, para que normatizem as referências. Em seguida, são encaminhados para a revisora de inglês, também terceirizada, de modo a verificar se estão corretos os artigos que serão publicados em inglês ou corrigir a tradução de título do artigo e abstract dos que serão publicados em português; e) A definição dos trabalhos que serão publicados é realizada pelo editor chefe. Eles são inseridos numa lista de artigos aprovados, conforme sistema online, e serão publicados no próximo número da Revista; f) Com a definição dos artigos que serão publicados na próxima edição da Revista, os mesmos serão disponibilizados pela gestora, por meio do sistema online, para que seja iniciado o processo de diagramação. Nesta fase, o departamento comercial precisa enviar os anúncios comerciais que serão veiculados no próximo número da Revista para compor o caderno de anúncios; g) O processo de revisão final é realizado após a diagramação, sendo de responsabilidade da empresa contratada, que deverá fornecer ao revisor final uma cópia prévia da Revista para análise, verificação e aprovação. Qualquer alteração necessária deverá ser corrigida de acordo com as especificações encontradas e fornecida nova prova para análise; h) A aprovação da plotter, ou seja, da impressão simples da Revista finalizada, é de responsabilidade do editor chefe; i) $\mathrm{O}$ envio da Revista Especializada aos stakeholders é feito via correio impresso, sendo de responsabilidade da Associação fornecer o mailing para esta distribuição; j) Todas as divergências encontradas na distribuição da Revista devem ser tratadas a fim de que sejam recebidas de fato pelos stakeholders.

Contudo, o resultado da análise do documento apresenta que sua descrição não é detalhada em todas as necessidades do projeto e do produto, principalmente, não sendo considerado no escopo as necessidades das partes interessadas (JOB; GOELLNER, 2015), por exemplo, os autores dos artigos e os anunciantes, o número total de artigos necessários para uma edição da Revista e sua própria produção gráfica. Portanto, o escopo do projeto não atende a todos os requisitos necessários de acordo com o previsto por Dinsmore (1992).

O terceiro processo da gestão do escopo propõe a criação de uma EAP, de modo que o trabalho e as entregas sejam subdivididos em partes menores facilitando a gestão. Esse processo não é realizado pela empresa, a gestora relata desconhecer a ferramenta, e justifica não haver necessidade na sua utilização, visto que o fluxo de trabalho mantém os mesmos terceirizados em média durante 15 anos, devido às especificações técnicas fundamentais para a produção bimestral de um periódico científico. Para a gestora, o uso de um cronograma é 
suficiente para o desenvolvimento do projeto, explicando, ainda, que tem o sistema utilizado para o envio de artigos, por mais que o mesmo não atenda a todas as necessidades da gestão do projeto. Todavia, as atividades decompostas pela EAP (CARVALHO; RABECHINI, 2011), são tomadas como base para o desenvolvimento do cronograma (PMI, 2013).

O processo de verificação do escopo que prevê a formalização e aceitação dos entregáveis, é realizado, muitas vezes, de modo informal, podendo sacrificar tempo, custo e desempenho (KERZNER, 2011). As aprovações e autorizações são realizadas por telefone, correio eletrônico interno e pelo próprio sistema utilizado para submissão dos artigos que tem apresentado sobrecarga e problemas operacionais.

O último processo previsto para a gestão do escopo está relacionado com o controle do escopo e gerenciamento das suas alterações. Este processo é executado pela gestora com base no cronograma do projeto para monitoramento do projeto e do produto. Também foi identificado controle da análise dos artigos pelo sistema de submissão. O que pode acarretar em mudança do escopo são os artigos que dependem de avaliação pelos revisores ou pelo próprio autor, que não tem cumprido os prazos determinados de 30 dias - esse prazo foi levantado na entrevista e não é descrito no escopo. Mas, nessas situações, não há definição de um responsável, como sugerido por Dinsmore (1992), que possa decidir a possível substituição do artigo, do revisor e mudança do escopo, para que o prazo ou desempenho do projeto não seja comprometido (KERZNER, 2011).

\section{Gestão do Tempo do Projeto}

O projeto de produção do periódico tem sofrido atrasos significativos, visto que não tem cumprido os prazos de circulação das edições estabelecidos na sua programação, que é parte integrante dos contratos comerciais de veiculação de anúncios. Além disso, a falta de pontualidade na publicação das edições também pode comprometer a avaliação da qualidade do periódico (FERREIRA; KRZYZANOWSKI, 2003; JOB; GOELLNER, 2015). A análise das edições de 2010 a 2014 da Revista Especializada constatou os atrasos na entrega dos projetos, conforme apresentado na Figura 3. 


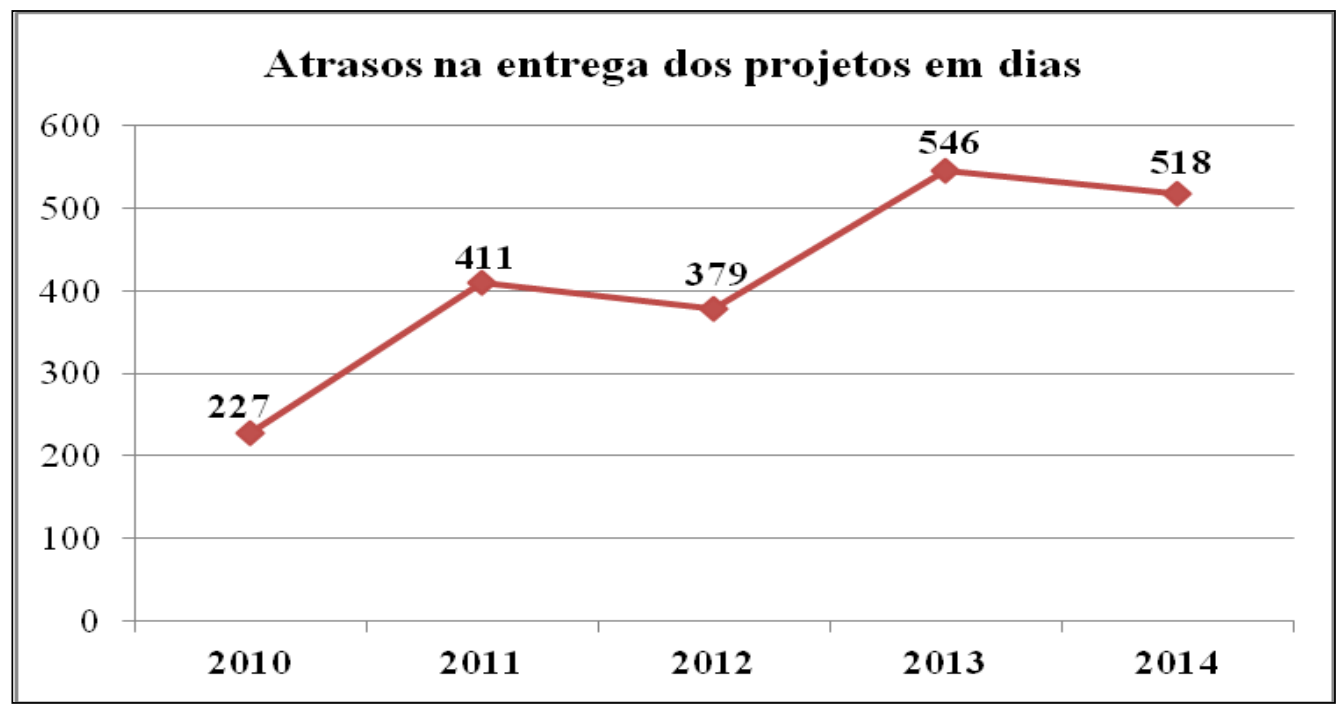

FIGURA 3 - Análise da periodicidade das edições

Fonte: os autores, pesquisa de campo.

Diante da análise dos resultados da Figura 3, a média de atrasos de cada edição nos últimos cinco anos é de, aproximadamente, 37, 68, 63, 91 e 86 dias, respectivamente, após o prazo planejado para encerramento do projeto. Este resultado também poderá causar impacto, por exemplo, na gestão de custo do projeto, conforme previsto por Kerzner (2011).

A gestão do tempo inclui os processos necessários para realizar o término de uma atividade ou fase do projeto no prazo determinado. Com esta finalidade, é preciso utilizar um cronograma de atividades que seja determinante nas datas de início e término do projeto. Para abordar a gestão do tempo do projeto de produção da Revista Especializada, foram utilizados os processos para a definição das atividades, o sequenciamento das atividades, a estimativa dos recursos das atividades, a estimativa de duração das atividades, o desenvolvimento do cronograma e o controle do cronograma, com base no PMI (2012).

O primeiro processo que define as atividades que irão produzir as entregas do projeto é realizado de maneira informal. Não foram identificados registros oficiais que permitiriam uma análise desse processo. No processo em que as atividades definidas devem ser sequenciadas também não há formalidade. A justificativa da gestora é que todas as atividades, sequências e relacionamento já são do conhecimento de todos os envolvidos, não sendo necessária a formalização desse processo.

Em seguida, o processo que estima os recursos necessários para realizar cada atividade, igualmente não é realizado. O próximo processo busca estimar a duração mais próxima para que cada atividade seja desenvolvida. Este processo é desenvolvido, conforme abordagem da gestora, com base na sua própria experiência, não sendo consultados outros envolvidos, e sem qualquer formalidade ou registro de documentos.

O processo do cronograma prevê, dentre outros, a sequência de atividades com os recursos previstos. O projeto utiliza o Cronograma Estruturado (CE), determinado pelo SGQ, que estima a realização e duração de apenas algumas atividades a serem desenvolvidas no 
período de dois meses. A estrutura é utilizada nos projetos futuros, atualizando, apenas, os meses correspondentes à realização. As atividades inerentes ao projeto são divididas em seis categorias: 1) Planejamento da operação: relaciona as atividades iniciadas pela avaliação dos trabalhos submetidos, todas as revisões necessárias, a diagramação e editoração, aprovação da plotter, impressão e distribuição; 2) Procedimentos prévios: submissão de trabalhos; 3) Critérios para medição e monitoramento: considera as atividades do processo de produção gráfica e distribuição; 4) Verificação e liberação: aprovação final do projeto; 5) Distribuição da Revista; 6) Pós entrega: tratar as devoluções dos correios. O CE relaciona "quem" é o responsável por cada atividade, apresentando, ainda, para "quando" foi "planejado" e "realizado". Para cada categoria são definidos o responsável e o prazo para execução.

Pelo histórico, não foi identificada a aprovação do CE pelo editor chefe, o que é argumentado pela gestora como não sendo necessário, o que contradiz a Xavier e Chueri (2008). Destaca-se o desconhecimento por parte da técnica responsável pela editoração e diagramação da existência do cronograma do projeto, do prazo previsto para sua atividade e, igualmente, do planejamento e prazos do projeto. Segundo a técnica, as atividades de diagramação são realizadas, "rapidamente", e a editoração é que "consome" mais tempo. Contudo, ela não soube definir o prazo efetivo para cumprir com todas as atividades. Também foi identificado que a mesma tem desenvolvido atividades que não fazem parte de suas atribuições, o que pode acarretar em atrasos nas entregas de sua responsabilidade.

O último processo realizado na gestão do tempo é o controle e monitoramento do cronograma. A gestora afirma que o uso do CE possibilita uma visão melhor de qual processo está comprometendo o desempenho do projeto, conforme previsto por Xavier e Chueri (2008), determinando como ponto crítico constante, o cumprimento dos prazos na fase de revisão dos artigos realizada pela comissão editorial. Contudo, foi identificada a falta de acompanhamento e monitoramento do $\mathrm{CE}$, fato que pode conduzir ao comprometimento do escopo e dos custos do projeto (CARVALHO; RABECHINI, 2011).

\section{Gestão dos Custos do Projeto}

Para abordar a gestão dos custos de produção da Revista Especializada, foram utilizados os processos para estimar os custos, determinar o orçamento e controlar os custos (PMI, 2013). Essa gestão se refere à previsão de custos necessários para cumprir com as atividades planejadas no cronograma e no orçamento aprovado para a realização do projeto. Não foram identificados integrações, previsões, controles gerenciais dos custos e orçamentos dos projetos como sugerido por Kerzner (2011), Xavier e Cheri (2008) e Carvalho e Rabechini (2011), tais como, fluxo de caixa, planilhas e cronogramas de desembolso.

$\mathrm{Na}$ análise financeira dos projetos foram adotados os relatórios finais de receitas e despesas. Constatou-se que os projetos foram encerrados com um déficit aproximado de $10 \%$ em 2010 e 2011, seguindo de uma redução progressiva de 41\% (2012), 62\% (2013) e 75\% (2014), isto é, abaixo da receita necessária para cobrir os custos dos projetos (Figura 4). 


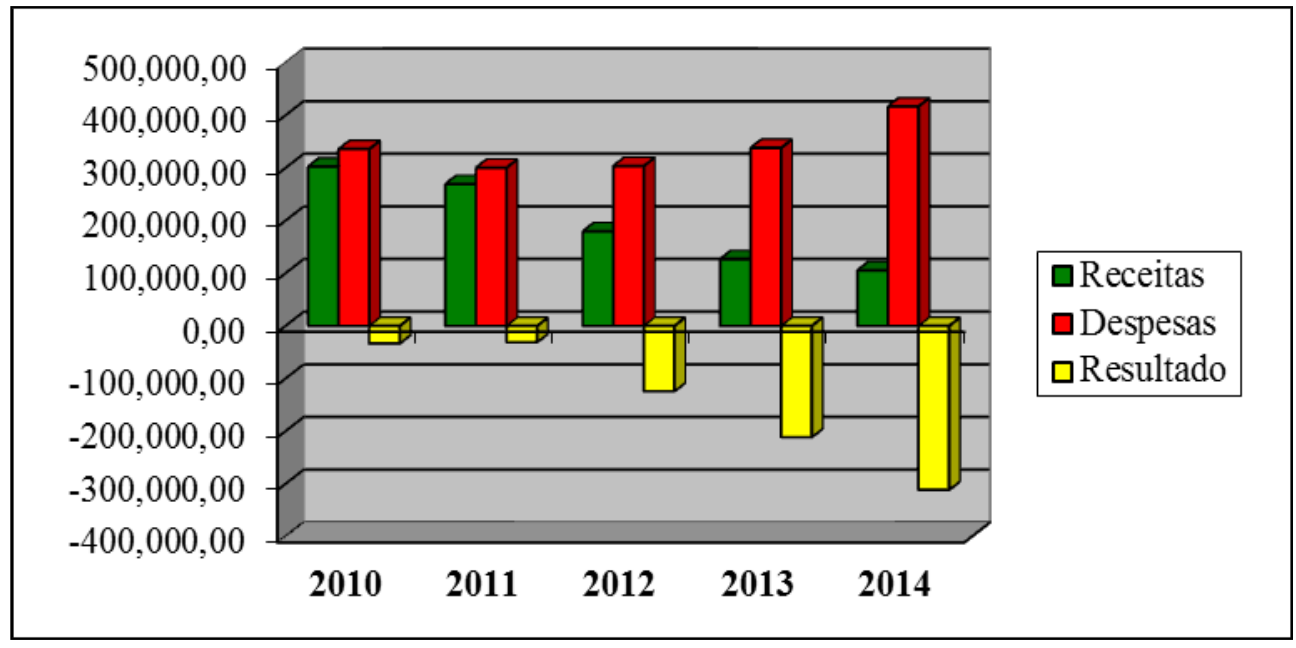

FIGURA 4: Resultado financeiro anual dos projetos

Fonte: os autores, pesquisa de campo.

Também foi constatada uma redução de $11 \%$ na receita de 2010 para 2011, 33\% de 2011 para 2012, 29\% de 2012 para 2013, e 17\% de 2013 para 2014, demonstrando que a veiculação de anúncios comerciais que contribui com a maior parte dos custos de produção tem caído significativamente. Cabe destacar que a redução na receita é de $65 \%$ se comparado os valores de 2010 e 2014. Relatórios de pesquisa do SGQ identificaram insatisfação dos patrocinadores quanto aos expressivos atrasos da Revista por comprometer os seus projetos de marketing, incentivando-os a veicularem seus anúncios em outros periódicos, mesmo não sendo científicos e não indexados em bases de dados, mas que mantém sua periodicidade.

O processo de estimativa dos custos para que as atividades sejam finalizadas não é realizado. O próximo processo previsto para a gestão dos custos é determinar o orçamento para que os custos fiquem autorizados; todavia, ele não é aplicado. Consequentemente, o último processo que consiste no monitoramento do desenvolvimento do projeto e gestão dos custos, também é inexistente, indo de encontro ao proposto pelo PMBoK® (PMI, 2013).

A justificativa da gestora para não utilizarem ferramentas gerenciais de controle financeiro é que a alta direção encarou esses déficits como uma contribuição da empresa para incentivar a produção científica brasileira, encarando como um benefício a mais para os stakeholders e uma contribuição para a sociedade. Todavia, não considerar as previsões de custo pode ocasionar perda de tempo e de recursos em atividades não previstas e desnecessárias. Neste sentido, a gestão do tempo se torna crítica (KHANG; MYINT, 1999), a avaliação do desempenho do projeto é comprometida (XAVIER; CHUERI, 2008), e o projeto está sujeito a ser encerrado fora do prazo (DINSMORE; CAVALIERI, 2008).

\section{Proposições de Melhorias}

A análise do projeto de produção da Revista Especializada permitiu identificar problemas nos processos relacionados aos objetivos primários da gestão de projetos. Nesse sentido, algumas proposições de melhorias podem ser sugeridas visando uma melhor gestão 
do projeto, sendo aqui apresentadas. Como primeira iniciativa, propõe-se realizar uma sistemática coleta dos requisitos necessários para o projeto de modo que o seu escopo seja elaborado através de uma estrutura completa e detalhada, incluindo, ainda, os entregáveis e os respectivos responsáveis.

Deve ser considerada a possibilidade de substituição de um artigo previsto no escopo do projeto de produção da Revista, o que acarreta em mudança do escopo, tornando-se necessário o seu monitoramento e controle. O cronograma também deve ser gerenciado diariamente de modo a identificar, antecipadamente, possíveis atrasos, facilitando a tomada de decisões. Quanto a não utilização da ferramenta EAP, sugere-se que a mesma seja adotada, podendo, inclusive, ser representada por meio de tabelas que são de fácil manuseio, se a organização não tiver interesse em investir em um programa informatizado específico. A adoção desse procedimento permitirá uma melhor decomposição do escopo do projeto, além de contribuir com a elaboração detalhada de todas as atividades do cronograma do projeto.

Mesmo com sua finalidade não lucrativa e entendimento do contexto institucional da organização, indica-se a adoção dos processos que compõem a gestão dos custos. Com a gestão dos custos e a integração com as gestões do escopo e prazo, tem-se a expectativa de redução dos déficits dos projetos e um melhor gerenciamento das receitas com veiculação de anúncios comerciais.

Entendendo que a revisão dos trabalhos submetidos para avaliação e revisão é um ponto crítico em todos os projetos analisados, recomenda-se que esse processo seja visto como um projeto único, ou seja, tendo início e término programados, e necessitando de uma exclusiva gestão do escopo, do tempo e dos custos. Com essa conduta, acredita-se que o gerenciamento independente dos artigos submetidos possa ocorrer de maneira mais ágil, de modo a não comprometer o projeto de produção da Revista.

Adicionalmente, sugere-se que a gestora responsável pelo escopo do projeto adquira conhecimentos das boas práticas da gestão de projetos, conforme apontado por Dinsmore (1992) e Ruggeri (2011). No Quadro 3 são apresentados os resultados das análises realizadas no projeto em estudo sobre a aplicação dos processos das gestões de escopo, tempo e custos, considerados pelo PMI (2013), que corroboram com as abordagens realizadas nesta seção.

QUADRO 3 - Aplicação dos objetivos primários da gestão de projetos no caso analisado

\begin{tabular}{|l|l|l|}
\hline \multicolumn{1}{|c|}{ Processos da Gestão do Escopo } & \multicolumn{1}{c|}{ Revista Especializada } & \multicolumn{1}{c|}{ Impacto } \\
\hline Coletar os requisitos & Aplicação informal & Objetivo \\
\hline Definir o escopo & Aplicado com restrições & Objetivo \\
\hline Criar a EAP & Não aplicado & Cronograma \\
\hline Verificar o Escopo & Aplicação informal & Tempo, custo e desempenho \\
\hline Controlar o Escopo & Aplicação informal & Prazo e desempenho \\
\hline \multicolumn{1}{|c|}{ Processos da Gestão do Tempo } & \multicolumn{1}{c|}{ Revista Especializada } & \multicolumn{1}{c|}{ Impacto } \\
\hline Definir as atividades & Aplicação informal & Entregas do projeto \\
\hline Sequenciar as atividades & Aplicação informal & Cronograma \\
\hline Estimar os recursos & Não aplicado & Entregas do projeto \\
\hline Estimar as durações das atividades & Aplicação informal & Cronograma \\
\hline Desenvolver o cronograma & Aplicado com restrições & Objetivo e desempenho \\
\hline
\end{tabular}




\begin{tabular}{|l|l|l|}
\hline Controlar o cronograma & Aplicado com restrições & Escopo e custos \\
\cline { 1 - 2 } \multicolumn{1}{|c|}{ Processos da Gestão dos Custos } & Revista Especializada & \multirow{2}{*}{ Impacto } \\
\hline Estimar os custos & Não aplicado & \multirow{2}{*}{ Tempo, custo e desempenho } \\
\cline { 1 - 2 } Determinar o orçamento & Não aplicado & \\
\cline { 1 - 2 } Controlar os custos & Não aplicado & \\
\hline
\end{tabular}

Fonte: os autores, pesquisa de campo.

Esse resultado permite uma avaliação das implicações nos cinco grupos de processos da gestão de projetos (Quadro 4), tendo como referência o PMI (2013), destacando-se os seguintes pontos: a) $\mathrm{O}$ grupo de iniciação foi atendido de forma restrita, devido à aplicação informal da maioria dos processos da gestão do escopo e não aplicação dos processos da gestão dos custos, resultado que poderá comprometer o escopo, os recursos financeiros e objetivos iniciais da Revista Especializada; b) Para o grupo de planejamento, a aplicação foi parcial devido à informalidade na maioria dos processos e às restrições no cumprimento de outros, o que compromete a elaboração do escopo total da Revista e de seu objetivo refinado. Sobressai-se o comprometimento da elaboração do escopo, do cronograma, dos custos e do plano de gerenciamento da Revista; c) Considerando a parcialidade no planejamento, o grupo de execução será afetado e a conclusão do trabalho ficará comprometida; d) $\mathrm{O}$ grupo de monitoramento e controle não é realizado continuamente, comprometendo o progresso e o desempenho do projeto; e) No grupo de encerramento não há cumprimento do seu principal requisito, que é a formalização do encerramento de todos os grupos de processos.

QUADRO 4 - Aplicação dos grupos de processos da gestão de projetos no caso analisado

\begin{tabular}{|l|l|l|}
\hline \multicolumn{1}{|c|}{ Grupos de Processos } & \multicolumn{1}{c|}{ Aplicação } & \multicolumn{1}{c|}{ Impacto } \\
\hline Iniciação & Parcial com informalidade & $\begin{array}{l}\text { Escopo, recursos financeiros e } \\
\text { objetivos. }\end{array}$ \\
\hline Planejamento & Parcial com informalidade & $\begin{array}{l}\text { Elaboração do escopo total, } \\
\text { objetivos e custos. }\end{array}$ \\
\hline Execução & Reflete a parcialidade do planejamento & $\begin{array}{l}\text { Comprometimento da conclusão } \\
\text { do trabalho. }\end{array}$ \\
\hline Monitoramento e Controle & Parcial e não contínua & Progresso e desempenho. \\
\hline Encerramento & Inexistente & Obrigações contratuais. \\
\hline
\end{tabular}

Fonte: os autores, pesquisa de campo.

Portanto, diante da análise dos resultados e das proposições de melhorias, acredita-se que a adoção dessas boas práticas contribua com um melhor processo de planejamento e, consequentemente, controle e monitoramento do projeto de produção da Revista Especializada. Essa expectativa torna-se promissora ao considerar a relação desses processos da gestão de projetos e as áreas do escopo, tempo e custo apresentada na Figura 1.

\section{CONSIDERAÇÕES FINAIS}

Este estudo objetivou analisar o processo de produção de um periódico científico, sob a ótica da gestão de projetos. O estudo de caso foi adotado como instrumento de aplicação na prática da metodologia da gestão de projetos, com o intuito de contribuir para um melhor planejamento e desenvolvimento do processo de produção de uma Revista Especializada da área médica. A análise foi fundamentada na tríplice restrição de escopo, prazo e custo, bem 
como na aplicação dos grupos de processos de gerenciamento de projetos.

Os resultados sob a ótica dos processos e das ferramentas da gestão de projetos demonstra que a organização faz uso parcial, mas podem ser considerados embrionários no que se refere ao planejamento geral do projeto, especialmente por não realizar nenhum dos processos de gestão dos custos. Na gestão de escopo e de tempo muitas das ferramentas são utilizadas de maneira informal, podendo ter como causa a falta de padronização de uma metodologia de gestão de projetos, a exemplo do PMBoK®. Este resultado causa impacto negativo na gestão do projeto de produção da Revista Especializada, comprometendo também a captação de recursos financeiros, sua periodicidade e, consequentemente, a avaliação de desempenho (forma), colocando em risco a permanência do periódico indexado nas principais bases de dados nacionais e internacionais.

Pelas proposições de melhorias apresentadas é possível afirmar que existem algumas facilidades que poderão contribuir para a implantação e adequação do processo de produção do periódico analisado nas áreas de escopo, tempo e custo, para os projetos futuros. Essas práticas não eliminarão as já existentes (como as implantadas pelo SGQ), mas poderão contribuir para que sejam desenvolvidas de maneira formal e sistêmica.

Tendo por base a cultura de uma organização sem fins lucrativos, bem como o caráter científico do projeto, o estudo tem limitações quanto à definição de sucesso ou fracasso neste contexto. Porém, com a implantação dos processos de gestão de custo, o desempenho do projeto poderá ser medido, o que também pode ocorrer por meio da análise da gestão do tempo. Outra limitação refere-se à prática de caso único, não permitindo extrapolar os resultados nem aferir generalizações. Para estudos futuros, recomenda-se analisar os processos e ferramentas de outras áreas de conhecimento, a exemplo da integração, por se relacionar com os cinco grupos de processos da gestão de projetos, e das múltiplas partes interessadas (stakeholders) no projeto.

Assim, tem-se a expectativa de que este estudo, por meio de sua análise teóricoempírica, possa levantar empenho de pesquisadores e gestores interessados no processo de produção de periódicos científicos, bem como na aplicação prática da metodologia da gestão de projetos em outros contextos e culturas organizacionais, a exemplo de projetos desenvolvidos por organizações sem fins lucrativos, já que são considerados elementares estudos com essa abordagem.

\section{REFERÊNCIAS}

ALMEIDA, Leandro; MIGUEL, Paulo Cauchick; DE CARVALHO, Marly Monteiro. Aplicação do gerenciamento de projetos no processo de desenvolvimento de novos produtos - um caso exploratório. Produto \& Produção, Porto Alegre, v. 9, n. 2, p. 153-166, jun. 2008 .

BIANCOLINO, César Augusto et al. Protocolo para elaboração de relatos de produção 
técnica. Revista de Gestão e Projetos, São Paulo, v. 3, n. 2, p. 294-307, maio/agosto. 2012.

CARVALHO, Marly Monteiro; RABECHINI JR., ROQUE. Fundamentos em gestão de projetos: construindo competências para gerenciar projetos. 3. ed. São Paulo: Atlas, 2011.

CRAWFORD, Lynn; POLLACK, Julien; ENGLAND, David. Uncovering the trends in project management: Journal emphases over the last 10 years. International Journal of Project Management, East Horsley, v. 24, p. 175-184, 2006.

DINSMORE, Paul Campbell. Gerência de Programas e de Projetos. São Paulo: Pini, 1992.

DINSMORE, Paul Campbell; CAVALIERI, Adriane. Como se tornar um profissional em gerenciamento de projetos. 2. ed. Rio de Janeiro: Qualitymark, 2008.

FERREIRA, Maria Cecília Gonzaga; KRZYZANOWSKI, Rosaly Favero. Periódicos científicos: critérios de qualidade. Pesquisas de Odontologia Brasileira, São Paulo, v. 17 (Supl 1), p. 43-48, 2003.

FERREIRA NETO, Amarílio; NASCIMENTO, Ana Claudia Silverio. Periódicos científicos da Educação Física: Proposta de Avaliação. Movimento, Porto Alegre, v. 8, n. 2, p. 35-49, maio/ago. 2002.

IBBS, C. William; KWAK, Young H. Measuring project management's return on investment. PM NETwork, Newton Square, PA, v.1, 11, n. 11, p. 36-38, Nov. 1997.

IKA, Lavagnon A. Project Success as a Topic in Project Management Journals. Project Management Journal, Quebec, v. 40, n. 4, p. 6-19, 2009.

JHA, K. N.; IYER, K. C. Commitment, coordination, competence and iron triangle. International Journal of Project Management, East Horsley, v. 25, n. 5, p. 527-540. 2007.

JOB, Ivone; GOELLNER, Silvana Vilodre. Proposta de instrumento para avaliação da gestão editorial das revistas científicas brasileiras em educação física e ciências do esporte. Rev. digit bibliotecon. Cienc. Inf., Campinas, SP, v. 13, n. 1, p. 207-224, jan/abr. 2015.

KERZNER, Harold. Gerenciamento de Projetos: uma abordagem sistêmica para planejamento, programação e controle. 10. ed. São Paulo: Blucher, 2011.

KHANG, Do Ba; MYINT, Yin Mon. Time, cost and quality trade-off in Project management: a case study. International Journal of Project Management, East Horsley, v. 17, n. 4, p. 249-256, 1999. 
KRZYZANOWSKI, Rosaly Favero; FERREIRA, Maria Cecília Gonzaga. Avaliação de periódicos científicos e técnicos brasileiros. Ciência da Informação, Brasília, v. 27. n. 2, p. 165 - 175, maio/ago. 1998.

MUELLER, Suzana Pinheiro Machado. O círculo vicioso que prende os periódicos nacionais. DataGramaZero: Revista de Ciência da Informação, Rio de Janeiro, n.0, dez. 1999. Disponível em: 〈http://eprints.rclis.org/handle/10760/6189>. Acesso em: 20 jun. 2015.

MUNNS, A. K.; BJEIRMI, B. F. The role of project management in achieving project success. International Journal of Project Management, East Horsley, v. 14, n.2, p. 81-88, 1996.

PMI - Project Management Institute. A guide to the project management body of knowledge. 5.ed. Newtown Square, Pennsylvania: PMI, 2013.

RABECHINI JR, Roque; CARVALHO, Marly Monteiro; LAURINDO, Fernando José B. Fatores críticos para implementação de gerenciamento por projetos: o caso de uma organização de pesquisa. Revista Produção, São Paulo, v.12, n.2, p. 28-41, 2002.

RUGGERI, Renê. G. Gerenciamento de projetos no terceiro setor. Rio de Janeiro: Brasport, 2011.

SHENHAR, Aron. J.; DVIR, D. Reinventando gerenciamento de projetos: a abordagem diamante ao crescimento e inovação bem-sucedidos. São Paulo: M. Books, 2010.

XAVIER, Magno da Silva; CHUERI, Luciana de O. Vilanova Metodologia de gerenciamento de projetos no terceiro setor: uma estratégia para a condução de projetos. 1 . ed. Rio de Janeiro: Brasport, 2008.

YIN, Robert K. Estudo de caso: planejamento e métodos. 4. ed. Porto Alegre: Bookman, 2010.

\section{AGRADECIMENTOS}

O presente trabalho foi realizado com o apoio da CAPES, do CNPq, e do Fundo de Apoio à Pesquisa - FAP/UNINOVE.

Como citar este documento:

LACERDA, Fabrício Martins; MARTENS, Cristina Dai Prá; MACCARI, Emerson Antonio. A gestão de projetos como apoio ao processo de produção de um periódico científico. Revista Digital de Biblioteconomia e Ciência da Informação, Campinas, SP, v. 13, n. 3, p. 612-631, set. 2015. ISSN 1678-765X. Disponível em: <http://periodicos.sbu.unicamp.br/ojs/index.php/rdbci/article/view/8639459> Acesso em: 18 Set. 2015. 